\title{
Antimicrobial resistance to Neisseria gonorrhoeae in Canada: 2009-2013
}

\author{
Martin $\mathbf{I}^{1, *}$, Sawatzky $\mathbf{P}^{1}$, Liu $\mathbf{G}^{1}$, Mulvey $\mathrm{MR}^{1}$ \\ ${ }^{1}$ National Microbiology Laboratory, Public Health Agency of Canada, Winnipeg, MB \\ *Correspondence: Irene.Martin@phac-aspc.gc.ca
}

\begin{abstract}
Background: Gonorrhea is on the rise in Canada. Treatment has been complicated by the fact that Neisseria gonorrhoeae has acquired resistance to many antibiotics, including penicillin, tetracycline, erythromycin and ciprofloxacin. The emergence of isolates with decreased susceptibilities to the third generation cephalosporins and reports of treatment failures in Canada and around the world are cause for concern.
\end{abstract}

Objective: To assess the resistance levels of common antibiotics to $N$. gonorrhoeae and to observe trends in resistance and/or decreased susceptibility to ciprofloxacin, third generation cephalosporins and azithromycin.

Methods: Laboratory surveillance data for $N$. gonorrhoeae isolates submitted by provincial microbiology laboratories to the National Microbiology Laboratory (NML) from 2009-2013 were compared.

Results: Since 2009, there has been an overall rise in antibiotic-resistant $N$. gonorrhoeae. In $2013,24.3 \%$ of the isolates were resistant to erythromycin, $18.9 \%$ were resistant to penicillin, $33.0 \%$ were resistant to tetracycline, and $29.3 \%$ were resistant to ciprofloxacin. The percentage of isolates with decreased susceptibility to ceftriaxone $(\geq 0.125 \mathrm{mg} / \mathrm{L})$ and/or cefixime $(\geq 0.25 \mathrm{mg} / \mathrm{L})$ was $3.9 \%$ in 2013 . This number represents a decrease from $5.9 \%$ in 2012 and $7.6 \%$ in 2011 . The proportion of azithromycin resistant (MIC $\geq 2 \mathrm{mg} / \mathrm{L}$ ) N. gonorrhoeae isolates increased from $0.4 \%$ in 2009 to $1.2 \%$ in 2013.

Conclusion: Resistance to erythromycin, penicillin, tetracycline and ciprofloxacin is common. Decreased susceptibility to ceftriaxone and/or cefixime is now almost $4 \%$ and azithromycin resistance is emerging but remains low at $1.2 \%$. These results have informed the gonococcal infection treatment recommendations in the Canadian Guidelines on Sexually Transmitted Infections.

\section{Introduction}

N. gonorrhoeae, the causative agent of gonorrhea, is the second most commonly reported bacterial sexually transmitted infection in Canada and rates of reported cases have more than doubled between 1997 and 2012 (1).

The treatment and control of gonorrhea is complicated by the ability of $N$. gonorrhoeae to evolve and develop resistance to many of the antibiotics used to treat it $(2,3)$. The emergence of isolates with decreased susceptibilities to the cephalosporins $(4,5,6,7)$ and reports of treatment failures in Canada $(8)$ and around the world raises the possibility of gonorrhea infections becoming untreatable in the future. The emergence of highlevel azithromycin resistant ( $\geq 256 \mathrm{mg} / \mathrm{L}$ ) $N$. gonorrhoeae has been reported internationally (9) and isolates with this high level azithromycin resistance have now been identified in Canada.

The number of cultures available for antimicrobial susceptibility testing is on the decline due to the shift from the use of culture to Nucleic Acid Amplification Test (NAAT) for the diagnosis of gonorrhea. This is of concern as $N$. gonorrhoeae cultures are required for antimicrobial susceptibility testing and some jurisdictions in Canada no longer maintain the capacity to culture this organism. In fact, over $70 \%$ of gonococcal infections in Canada are now diagnosed using NAAT and therefore antimicrobial susceptibility data in these jurisdictions are not available. The National Microbiology Laboratory (NML), in collaboration with the provincial laboratories, has been monitoring the antimicrobial susceptibilities of N. gonorrhoeae since 1985. 
The objective of this report is to summarize the trends in antimicrobial resistance to gonorrhea infections in Canada between 2009 and 2013. It is based on the National Surveillance of Antimicrobial Susceptibilities of Neisseria gonorrhoeae Annual Summary 2013 prepared by the NML, Public Health Agency of Canada (PHAC) (10).

\section{Methods}

\section{Data collection}

Provincial public health laboratories submitted a total of 5,518 viable N. gonorrhoeae isolates to the NML for antimicrobial susceptibility testing as part of the passive National Neisseria gonorrhoeae Surveillance Program between 2009 and 2013 (2009, N=913; 2010, N=1,233; 2011, N=1,158; 2012, N=1,031; 2013, N=1,183). $N$. gonorrhoeae isolates are submitted to the NML when the provincial laboratories identify resistance to at least one antibiotic or if the provincial laboratories do not perform any antimicrobial susceptibility testing. Submission of isolates is voluntary and is not standardized across the country. The overall interpretation of the results is difficult due to the limitations related to the isolates available for testing. Therefore, the total number of isolates cultured in all provinces was used as the denominator to calculate resistance proportion (2009, $N=3,106 ; 2010, N=2,970$; 2011, $N=3,360 ; 2012, N=3,036 ; 2013, N=3,195)$.

MICs were determined by agar dilution (11) and resistance was defined according to the Clinical and Laboratory Standards Institute (11) except for erythromycin (12) and azithromycin (13). Decreased susceptibility breakpoints for ceftriaxone and cefixime were based on WHO definitions (14). Common abbreviations for the different types of resistance have been developed (Table 1).

Table 1: Abbreviations and definitions for the different types of Neisseria gonorrhoeae antimicrobial resistance

\begin{tabular}{|c|c|c|}
\hline Abbreviation & Term in full & Definition \\
\hline PPNG & Penicillinase-Producing N. gonorrhoeae & $\begin{array}{l}\text { Pen MIC } \geq 2.0 \mathrm{mg} / \mathrm{L}, \beta \text {-lactamase positive, } \beta \text {-lactamase } \\
\text { plasmid }(3.05,3.2 \text { or } 4.5 \text { Mdal plasmid })\end{array}$ \\
\hline TRNG & $\begin{array}{l}\text { Tetracycline Resistant N. gonorrhoeae (plasmid- } \\
\text { mediated) }\end{array}$ & Tet MIC $\geq 16.0 \mathrm{mg} / \mathrm{L}, 25.2 \mathrm{Mdal}$ plasmid, TetM PCR positive \\
\hline CMRNG & $\begin{array}{l}\text { Chromosomal Mediated Resistant } \\
\text { N. gonorrhoeae }\end{array}$ & $\begin{array}{l}\text { Pen MIC } \geq 2.0 \mathrm{mg} / \mathrm{L}, \text { Tet } \mathrm{MIC} \geq 2.0 \mathrm{mg} / \mathrm{L} \text { but } \leq 8.0 \mathrm{mg} / \mathrm{L} \text { and } \\
\text { Ery MIC } \geq 2.0 \mathrm{mg} / \mathrm{L}\end{array}$ \\
\hline Probable CMRNG & $\begin{array}{l}\text { Probable Chromosomal Mediated Resistant } N \text {. } \\
\text { gonorrhoeae }\end{array}$ & $\begin{array}{l}\text { One of the MIC values of Pen, Tet, Ery }=1 \mathrm{mg} / \mathrm{L} \text {, the other two } \\
\geq 2.0 \mathrm{mg} / \mathrm{L}\end{array}$ \\
\hline TetR & $\begin{array}{l}\text { Tetracycline Resistant } N \text {. gonorrhoeae } \\
\text { (chromosomal mediated) }\end{array}$ & Tet $\mathrm{MIC} \geq 2.0 \mathrm{mg} / \mathrm{L}$ but $\leq 8.0 \mathrm{mg} / \mathrm{L}$ \\
\hline CipR & Ciprofloxacin Resistant N. gonorrhoeae & Cip MIC $\geq 1.0 \mathrm{mg} / \mathrm{L}$ \\
\hline$A z R$ & Azithromycin Resistant N. gonorrhoeae & $A z M I C \geq 2.0 \mathrm{mg} / \mathrm{L}$ \\
\hline SpecR & Spectinomycin Resistant N. gonorrhoeae & Spec $R \geq 128 \mathrm{mg} / \mathrm{L}$ \\
\hline CxDS & $\begin{array}{l}\text { N. gonorrhoeae with decreased susceptibility to } \\
\text { Ceftriaxone }\end{array}$ & $\mathrm{Cx} \mathrm{MIC} \geq 0.125 \mathrm{mg} / \mathrm{L}$ \\
\hline CeDS & $\begin{array}{l}\text { N. gonorrhoeae with decreased susceptibility to } \\
\text { Cefixime }\end{array}$ & Ce MIC $\geq 0.25 \mathrm{mg} / \mathrm{L}$ \\
\hline
\end{tabular}




\section{Results}

Figure 1 shows the trends of antimicrobial susceptibilities of $N$. gonorrhoeae tested in Canada from 2009 to 2013.

Figure 1: Trends of antimicrobial susceptibilities of Neisseria gonorrhoeae tested in Canada from 2009 to 2013

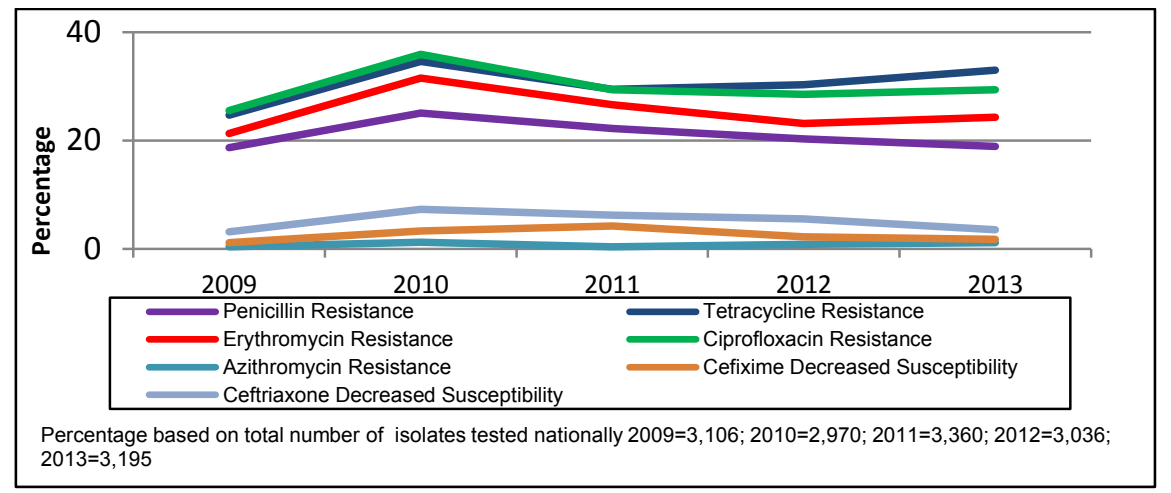

Of the 3,195 N. gonorrhoeae isolates cultured in public health laboratories across Canada in $2013,1,183$ presumptively resistant isolates were submitted to the NML. Of these, 1,153 were confirmed to be resistant to at least one antibiotic and 30 were susceptible which translates to $36.1 \%$ of all $N$. gonorrhoeae cases diagnosed by culture as resistant $N$. gonorrhoeae.

Gender and age data was available for $99.5 \%$ of the 2013 isolates tested at the NML. Of these, $83.1 \%$ were males ranging from 1 month to 74 years of age. A total of $16.9 \%$ of isolates were from females aged 2 to 71 years.

\section{Third generation cephalosporins}

In 2013 , according to WHO definitions, $1.8 \%$ of isolates were identified as having decreased susceptibility to cefixime and $3.5 \%$ were identified as having decreased susceptibility to ceftriaxone. These rates are higher than they were in 2009 (1.2\% decreased susceptibility to cefixime and $3.1 \%$ decreased susceptibility to ceftriaxone), but lower than in 2011 (4.2\% decreased susceptibility to cefixime and $6.2 \%$ decreased susceptibility to ceftriaxone). In $2013,3.9 \%$ of isolates were identified with decreased susceptibility to ceftriaxone and/or cefixime decreasing from $5.9 \%$ in 2012 and $7.6 \%$ in 2011.

\section{Azithromycin}

Azithromycin resistant $N$. gonorrhoeae increased from $0.4 \%$ in 2009 to $1.2 \%$ in 2013. Between 2009 and 2012, five isolates with high-level azithromycin resistance (MIC $\geq 256 \mathrm{mg} / \mathrm{L}$ ) were identified in Canada. The modal MIC for azithromycin has remained at $0.5 \mathrm{mg} / \mathrm{L}$ each year between 2009 and 2012. In 2013, the modal decreased to $0.25 \mathrm{mg} / \mathrm{L}$.

In 2012, seven isolates with combined decreased susceptibility to cephalosporins and resistance to azithromycin were identified $(0.2 \%)$. In 2013 , eight $(0.3 \%)$ of these isolates were identified. These are the first isolates to emerge in Canada with both decreased susceptibility to cephalosporins and resistance to azithromycin thus threatening the success of currently recommended dual therapy treatment options.

\section{Other antibiotics}

The percentage of ciprofloxacin resistant isolates increased from $25.5 \%$ in 2009 to $29.3 \%$ in 2013 . Ciprofloxacin resistance increased from $1.3 \%$ in 2000 to a high of $36.0 \%$ in 2010 . The modal MIC of ciprofloxacin has shifted dramatically from $0.004 \mathrm{mg} / \mathrm{L}$ in 2004 to $16.0 \mathrm{mg} / \mathrm{L}$ in 2013 (data not shown). 
In $2009,21.3 \%$ of isolates were found to be erythromycin resistant. This percentage increased to $31.5 \%$ by 2010 and then decreased to $24.3 \%$ by 2013 . Penicillin resistance increased from $18.7 \%$ in 2009 , to $25.1 \%$ in 2010 and then decreased to $18.9 \%$ in 2013. Tetracycline resistance increased from $24.7 \%$ in 2009 to $34.6 \%$ in 2010 and then decreased to $33.0 \%$ in 2013. Of the 5,518 viable isolates tested at NML between 2009 and 2013, none showed resistance to spectinomycin.

In $2013,13.5 \%$ of isolates were classified as Chromosomal mediated resistant $N$. gonorrhoeae (CMRNG), a slight decrease from the $15.3 \%$ identified in 2009. Penicillinase-producing N. gonorrhoeae (PPNG) accounted for $4.3 \%$ in 2013 , increasing slightly from $2.5 \%$ in 2009 . Plasmid-mediated tetracycline resistant $N$. gonorrhoeae (TRNG) increased from $3.2 \%$ in 2009 to $8.8 \%$ of isolates in 2013 (Figure 2).

Figure 2: Trends in chromosomal and plasmid-mediated antimicrobial resistance in Neisseria gonorrhoeae in Canada from 2009 to 2013

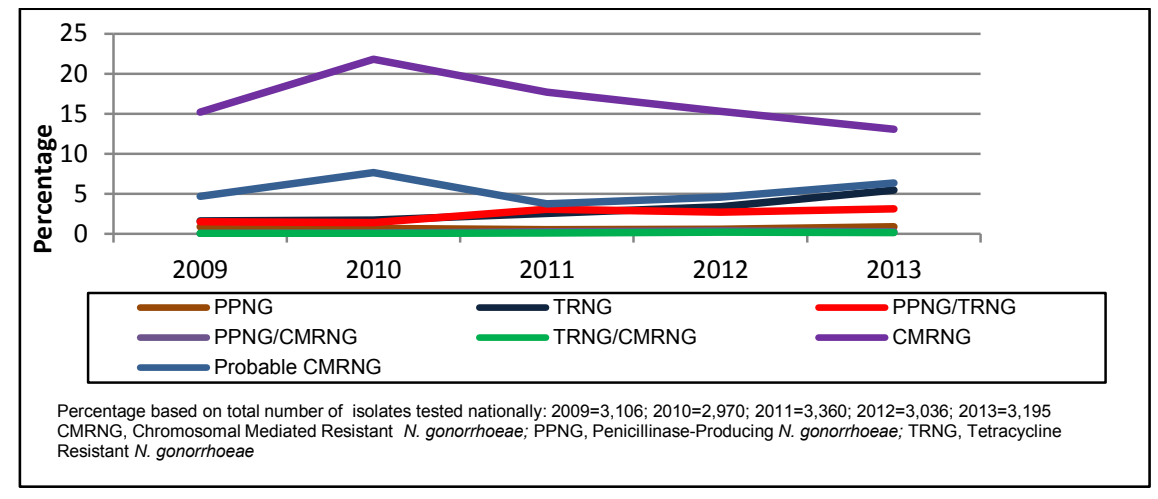

\section{Discussion}

The evolution of antimicrobial resistance in gonorrhea is complex and the emergence and spread of resistant isolates is a recognized global public health threat. Surveillance and monitoring of the antimicrobial susceptibilities of $N$. gonorrhoeae will continue to inform efforts to mitigate the impact of antimicrobial resistance in gonorrhea and guide therapeutic recommendations.

Reports of cefixime treatment failures and the observed MIC creep between 2001 and 2010 for both cefixime (from $0.016 \mathrm{mg} / \mathrm{L}$ to $0.125 \mathrm{mg} / \mathrm{L}$ ) and ceftriaxone (from $0.016 \mathrm{mg} / \mathrm{L}$ to $0.063 \mathrm{mg} / \mathrm{L}$ ) led to gonorrhea treatment changes. In 2011, the Canadian STI Guidelines issued updated recommendations for the use of combination gonorrhea therapy with $250 \mathrm{mg}$ ceftriaxone intramuscularly and azithromycin $1 \mathrm{~g}$ orally as the first-line regimen in men-who-have-sex-with men (MSM) and in pharyngeal infections (15).

Since the 2011 changes to gonorrhea treatment recommendations in Canada there has been a decrease in the proportion of isolates with elevated MICs to the cephalosporins. In $2011,7.6 \%$ of isolates exhibited decreased susceptibility to ceftriaxone and/or cefixime according to the WHO definition. This decreased to $5.9 \%$ in 2012 and further declined to $3.9 \%$ of isolates tested in 2013.

Fortunately, dropping rates of reduced cefixime susceptibility are also being seen elsewhere. For example, the US reported declines to decreased cefixime susceptibility from $3.9 \%$ in 2010 to $2.9 \%$ in the first half of 2012 (16). The UK reported the prevalence of isolates with decreased cefixime susceptibility dropped from $17.1 \%$ in 2010 to $10.8 \%$ in 2011 (17).

Enhancing surveillance to include linked epidemiological and laboratory data will assist with the limitations in the current passive surveillance system regarding data representativeness and interpretation. These improvements to the gonococcal surveillance program are expected with the Enhanced Surveillance of Antimicrobial Resistant Gonorrhea (ESAG) program beginning in 2014. 


\section{Acknowledgements}

The full report was prepared by the National Microbiology Laboratory and the Centre for Communicable Diseases and Infection Control, Infectious Disease Prevention and Control Branch, Public Health Agency of Canada. Its publication would not have been possible without the collaboration of all provinces and territories through the Canadian Public Health Laboratory Network (CPHLN), whose continuous contribution to National Neisseria gonorrhoeae Surveillance Program is greatly appreciated.

\section{Conflict of interest}

None

\section{Funding}

This work was supported by the Public Health Agency of Canada.

\section{References}

(1) Public Health Agency of Canada. Notifiable Diseases On-Line. 2014. http://dsol-smed.phac-aspc.gc.ca/dsolsmed/ndis/charts.php?c=pl.

(2) Barry PM, Klausner JD. The use of cephalosporins for gonorrhoea: The impending problem of resistance. Expert Opin Pharmacother. 2009; 10:555-577.

(3) Tapsall J. Antibiotic resistance in Neisseria gonorrhoeae is diminishing available treatment options for gonorrhoea: Some possible remedies. Expert Rev Anti Infect Ther. 2006; 4:619-628.

(4) Golparian D, Hellmark B, Fredlund H, Unemo M. Emergence, spread and characteristics of Neisseria gonorrhoeae isolates with in vitro decreased susceptibility and resistance to extended-spectrum cephalosporins in Sweden. Sex Transm Infect. 2010; 86:454-460.

(5) Ison CA, Hussey J, Sankar KN, Evans J, Alexander S. Gonorrhoea treatment failures to cefixime and azithromycin in England, 2010. Euro Surveill. 2011; 16(14):pii=19833.

(6) Pandori M, Barry PM, Wu A, Ren A, Whittington WLH, Liska S, Klausner JD. Mosaic penicillin-binding protein 2 in Neisseria gonorrhoeae isolates collected in 2008 in San Francisco, California. Antimicrob Agents Chemother. 2009; 53:4032-4034.

(7) World Health Organization (WHO). Emergence of multi-drug resistant Neisseria gonorrhoeae: Threat of global rise in untreatable sexually transmitted infections. 2011. http://whqlibdoc.who.int/hq/2011/WHO_RHR_11.14_eng.pdf.

(8) Allen VG, Mitterni L, Seah C, Rebbapragada A, Martin IE, Lee C, Siebert H, Towns L, Melano RG, Lowe DE. Neisseria gonorrhoeae treatment failure and susceptibility to cefixime in Toronto, Canada. JAMA. 2013; 309:163-170.

(9) Chisholm SA, Neal TJ, Alawattegama AB, Birley HDL, Howe RA, Ison CA. Emergence of high-level azithromycin resistance in Neisseria gonorrhoeae in England and Wales. J Antimicrob Chemother. 2009; 64:353-358.

(10) Public Health Agency of Canada. National Microbiology Laboratory. 2014. National surveillance of antimicrobial susceptibilities of Neisseria gonorrhoeae annual summary 2013.

(11) Clinical and Laboratory Standards Institute. Performance standards for antimicrobial susceptibility testing: Twenty-third informational supplement M100-S24 Vol. 34. Wayne, PA: Clinical and Laboratory Standards Institute; 2014.

(12) Ehret JM, Nims LJ, Judson FN. A clinical isolate of Neisseria gonorrhoeae with in vitro resistance to erythromycin and decreased susceptibility to azithromycin. Sex Transm Dis. 1996; 23:270-272.

(13) Centers for Disease Control and Prevention. Sexually transmitted disease surveillance 2007 Supplement, gonococcal isolate surveillance project (GISP) Annual report 2007. Atlanta, GA: U.S. Department of Health and Human Services, Centers for Disease Control and Prevention, March 2009. http//www.cdc.gov/std/GISP2007/.

(14) World Health Organization (WHO). Global action plan to control the spread and impact of antimicrobial resistance in Neisseria gonorrhoeae. 2012. http://www.who.int/reproductivehealth/publications/rtis/9789241503501/en/.

(15) Public Health Agency of Canada, 2011. Important notice: Public health information update on the treatment of Gonococcal Infection. http://www.phac-aspc.gc.ca/std-mts/sti-its/alert/2011/alert-gono-eng.php.

(16) Kirkcaldy RD, Kidd S, Weinstock HS, Papp JR, Bolan GA. Trends in antimicrobial resistance in Neisseria gonorrhoeae in the USA: the Gonococcal Isolate Surveillance Project (GISP), January 2006-June 2012. Sex Transm Infect. 2013 Dec; 89 Suppl 4:iv5-10. 
(17) Ison CA, Town K, Obi C, Chisholm S, Hughes G, Livermore DM, Lowndes CM, GRASP Collaborative Group. Decreased susceptibility to cephalosporins among gonococci: Data from the Gonococcal Resistance to Antimicrobials Surveillance Programme (GRASP) in England and Wales, 2007-2011. Lancet Infect Dis. 2013; 13:762-8. 